\title{
MiR-557 downregulation lowered cell proliferation and malignancy in glioblastoma by targeting ADAM17
}

\author{
Zongping Li ${ }^{1}$, Hongyuan Liu', Zhi Tang ${ }^{2 *}$, Qi Zhong ${ }^{1}$, Xu Yang1, Ye Zhang ${ }^{1}$, \\ Pengcheng He${ }^{1}$, Xiaoyi Wang ${ }^{1}$ \\ ${ }^{1}$ Department of Neurosurgery, Mianyang Central Hospital, Mianyang City, ${ }^{2}$ Department of Neurosurgery, Yanting County \\ People's Hospital, Mianyang City, Sichuan Province 621600, China
}

*For correspondence: Email: tangzhi77896@126.com; Tel: +86-816-7227180

\begin{abstract}
Purpose: To examine the role of miR-557 in the pathogenesis and development of glioblastoma (GBM) and its potential regulatory mechanism. Methods: Dysregulation of miR-557 in GBM cells was determined using quantitative (real-time) PCR $(q P C R)$. Cell proliferative ability, migratory activity and invasive ability were measured using the MTT colorimetric assay, wound healing assay and Transwell chambers assay. The direct target mRNA of miR-557 was predicted, and further validated using TargetScan and luciferase assay, respectively.

Results: Compared with human astrocytes (HAs), the downregulation of miR-557 was observed in human GBM cell lines. In U-251MG and A172 cells that overexpressed miR-557 mimics, the level of proliferation was significantly reduced, the wound width was larger, and the number of invaded cells wan decreased than that of NC mimics. Predictive results from TargetScan and results of luciferase assay demonstrated that miR-557 directly targets the 3'-untranslated region (3'-UTR) of ADAM17. In A172 cells and U-251MG cells, the upregulation E-cadherin (E-cad) and the downregulation of $\mathrm{N}$ cadherin ( $N$-cad) and vimentin (Vim) were caused by miR-557 mimics as compared with NC mimics. Expression of ADAM17, NICD, HES1, and EGFR was downregulated by miR-557 mimics and upregulated by miR-557 inhibitors in A172 cells and U-251MG cells.

Conclusion: Downregulation of miR-557 accelerates GBM cell growth and malignancy by directly targeting ADAM17 3'-UTR, providing a prognostic and potential therapeutic factor for new drug discovery in GBM.
\end{abstract}

Keywords: MiR-557, Cell proliferation, Malignancy, Glioblastoma cells, ADAM17

This is an Open Access article that uses a fund-ing model which does not charge readers or their institutions for access and distributed under the terms of the Creative Commons Attribution License (http://creativecommons.org/licenses/by/4.0) and the Budapest Open Access Initiative (http://www.budapestopenaccessinitiative.org/read), which permit unrestricted use, distribution, and reproduction in any medium, provided the original work is properly credited.

Tropical Journal of Pharmaceutical Research is indexed by Science Citation Index (SciSearch), Scopus, International Pharmaceutical Abstract, Chemical Abstracts, Embase, Index Copernicus, EBSCO, African Index Medicus, JournalSeek, Journal Citation Reports/Science Edition, Directory of Open Access Journals (DOAJ), African Journal Online, Bioline International, Open-J-Gate and Pharmacy Abstracts

\section{INTRODUCTION}

Glioblastoma (GBM) is the most aggressive tumor in the brain and central nervous system [1]. GBM accounts for $80 \%$ of all malignant brain tumors [2] and almost $60 \%-75 \%$ of all astrocytomas [3]. The current standard of care for GBM is the combination of surgery, involvedfield radiotherapy, and temozolomide chemotherapy for up to six maintenance cycles for de novo patients [4]. However, drug resistance occurs in patients with recurrent 
cancer without effective treatment [4]. A variety of cell types occur in GBM, making it difficult to treat. Therefore, identification of biomarkers and target therapies is the therapeutic direction for GBM [3].

Many pathways contribute to the development of GBM. Among them, amplification of epidermal growth factor receptor (EGFR), one of the substrates of $A$ Disintegrin and metalloproteases 17 (ADAM17) [6], was observed in $30 \%-50 \%$ of cases with glioma [5]. Overexpression of ADAM17 and elevation of ADAM17 activity are observed in breast cancer, colon cancer, and GBM [6,7]. Overexpression of ADAM17 promoted the abilities in GBM stem cell migration and invasion and induced epithelialmesenchymal transition (EMT), which suggests the important role of ADAM17 in the development and progression of GBM $[7,8]$.

MiRNAs are classified of short noncoding RNAs (18-25 nucleotides) [9], which function as gene suppressors to downregulate the stability or translational efficiency of target genes by the 3'untranslated region (3'-UTR) [10,11]. Dysregulation in miRNAs was found in many pathological processes, including the development of cancers [12]. For instance, downregulation of miR-148 prevented cell proliferation and migration through targeting ITGA9, indicating an inhibitory effect on the development of GBM [13]. However, no studies considering the effects of miR-557 on GBM. Therefore, to elaborate the functional role of $\mathrm{miR}$ 557 in the pathogenesis and development of GBM and its potential regulatory mechanism.

\section{EXPERIMENTAL}

\section{Cell culture and cell transfection}

Human GBM cell lines (U-251MG, LN-229, A172, and T98G) and human astrocytes (HAs) were obtained from Ningbo Mingzhou Biotechnology Company (Ningbo, Zhejiang Province, China). Cells were cultured in DMEM (\# D6429, Thermo Fisher Scientific, Waltham, MA, USA) with the supplements of penicillin/streptomycin solution (1 $\%$, \#15240-062, Gibco, part of Thermo Fisher Scientific), nonessential amino acids (1\%, Invitrogen, Carlsbad, CA, USA), and fetal bovine serum (10 \%, FBS, \#S1820-500, Biowest, Nuaillé, France) at a controlled environment of $37^{\circ} \mathrm{C}$ in a humidifier (95\% air and $5 \% \mathrm{CO}_{2}$ ).

\section{Measurement of cell viability}

MTT assay was purchased from Sigma-Aldrich (St. Louis, MO, USA). Cells in the logarithmic growth phase were seeded in 96-well plates $(1 \times$ $10^{4}$ cells/well) at $37^{\circ} \mathrm{C}$ for $24 \mathrm{~h}$. After removing the culture medium, cells were washed, and complete medium $(400 \mu \mathrm{L})$ and MTT salt solution $(100 \mu \mathrm{L})$ were added and incubated $\left(37^{\circ} \mathrm{C}, 4 \mathrm{~h}\right)$. The absorbance (OD value) of each well at 570 $\mathrm{nm}$ was read by a microplate reader (Bio-Tek Instruments, Winooski, VT, USA).

\section{Wound healing and Transwell chambers assays}

For cell migration measurement, cells were transfected as described previously. A wound was formed on the bottom of each well by drawing a straight line with a $200 \mu \mathrm{L}$ pipette tip, followed by washing and the scratch width was measured. After incubation $\left(24 \mathrm{~h}, 37^{\circ} \mathrm{C}\right)$, the scratch width was measured again and photographed.

For Transwell chamber (8 $\mu \mathrm{m}$ pore size; Millipore, Burlington, MA, USA) assay, cells were transfected as described previously. $5 \times 10^{4}$ cells were seeded into the upper chamber with the FBS-free cell suspension $(200 \mu \mathrm{L})$ and complete medium $(750 \mu \mathrm{L})$ containing $10 \%$ FBS was added to the lower chamber. $24 \mathrm{~h}$ later, cells were fixed, stained and photographed.

\section{Quantitative (real time) polymerase chain reaction (qPCR)}

The extraction of total RNA from GBM cells was performed, followed by qPCR under conditions of 40 cycles of $95^{\circ} \mathrm{C}(10 \mathrm{~s}), 60^{\circ} \mathrm{C}(30 \mathrm{~s})$, and $72^{\circ} \mathrm{C}$ $(30 \mathrm{~s})$. The quantification of relative mRNA level was based on $2^{-\Delta \Delta C t}$ method [14] with primer sequences (Sigma-Aldrich) listed in Table1.

Table 1: Primer used in PCR study

\begin{tabular}{lll}
\hline $\begin{array}{l}\text { Gene } \\
\text { name }\end{array}$ & Forward (5'-3') & Reverse(5'-3') \\
\hline miR-557 & $\begin{array}{l}\text { GTTTGCACGG } \\
\text { GTGGGC }\end{array}$ & GAACATGTCTGCGT \\
U6 & CGCTCTC \\
& GCACATATAC & TTCACGAATTTGCG \\
& & \\
\hline
\end{tabular}

\section{Luciferase assay}

The DNA fragments containing the putative miR557 target site within the ADAM17 3'-UTR (wildtype (WT) or mutant (MUT)) was cloned into psiCHECK-2 vector (Promega, Madison, WI, USA). A172 and U-251MG cells were cotransfected with miR-557 or NC mimics and psiCHECH-2-WT-ADAM17 or psi-CHECH-2-MUTADAM17, and the luciferase assay was conducted using Dual-Luciferase Assay Kit (Promega). 


\section{Western blotting}

Protein was extracted and the concentration was measured. Total proteins $(5 \mu \mathrm{g})$ were separated and then transferred to membranes, followed by blocked with primary antibodies ( $4{ }^{\circ} \mathrm{C}$, overnight). The primary antibodies (anti-ADAM17 was obtained from Abcam, Cambridge, UK, the others were obtained from Cell Signaling Technology, Danvers, MA, USA) were: anti-Ecadherin (E-cad) (\#3195, 1:500 dilution), anti-Ncadherin (N-cad) (\#13116, 1:500 dilution), antivimentin (Vim) (\#5741, 1:1000 dilution), antiADAM17 (\#ab2051, 1:300 dilution), anti-NICD (\#4147, 1:1000 dilution), anti-HES1 (\#11988, 1:200 dilution), anti-EGFR (\#3197, 1:800 dilution), and anti- $\beta$-actin (\#4970, 1:5000 dilution). The membranes were then incubated with a secondary antibody (anti-rabbit IgG, $\# 3900$, 1:1000 dilution). The signal strength of protein bands was detected using an ECL kit (Promega).

\section{Statistical analysis}

Each experiment was set up in triplicate and repeated three times. For data (shown as mean \pm standard deviation (SD)) analysis, GraphPad 8.0 (GraphPad, San Diego, CA, USA) was used. Differences between two groups or multiple groups ( $>2$ groups) were analyzed using Student's $t$-test or one-factor analysis of variance. A $p$ value $<0.05$ was regarded as statistically significant.

\section{RESULTS}

\section{MiR-557 prevented proliferation of GBM cells}

The downregulation of miR-557 was observed in human GBM cell lines (U-251MG, LN-229, A172, and T98G cells) compared with normal HAs (Figure 1A). In U-251MG and A172 cells, miR557 expression was increased by miR-557 mimics in comparison of that of NC mimics (Figure 1B). Besides, the viability of U-251MG and A172 cells, and the reduction in the number of BrdU-positive cells was caused by miR-557 mimics (Figure 1C-1D).

\section{MiR-557 inhibited GBM cell migration and invasion}

After $24 \mathrm{~h}$ of transfection, the wound width was larger in U-251MG and A172 cells that transfection of miR-557 mimics than that of $\mathrm{NC}$ mimics (Figure 2A). Results from Transwell assay demonstrated that fewer cells were stained after transfection of miR-557 mimics than
NC mimics in both U-251MG and A172 cells (Figure 2B).
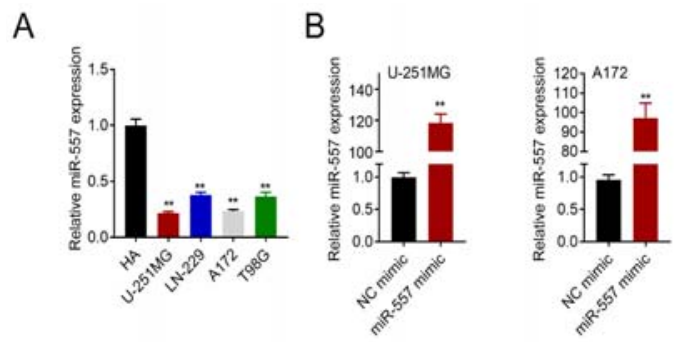

C
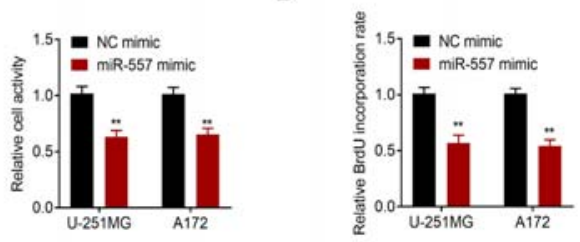

Figure 1: MiR-557 prevented the proliferation of GBM cells. (A) MiR-557 was downregulated in GBM cells lines; (B) MiR-557 was upregulated by miR-557 mimics in GBM cells; (C) The viability of GBM cells was reduced by miR-557 mimics; (D) BrdU incorporation rate was reduced by miR- 557 mimics in GBM cells; ${ }^{* *} p<0.01$ versus (vs.) HA or NC mimics. HA: human astrocytes; NC mimics: negative control of miR-557

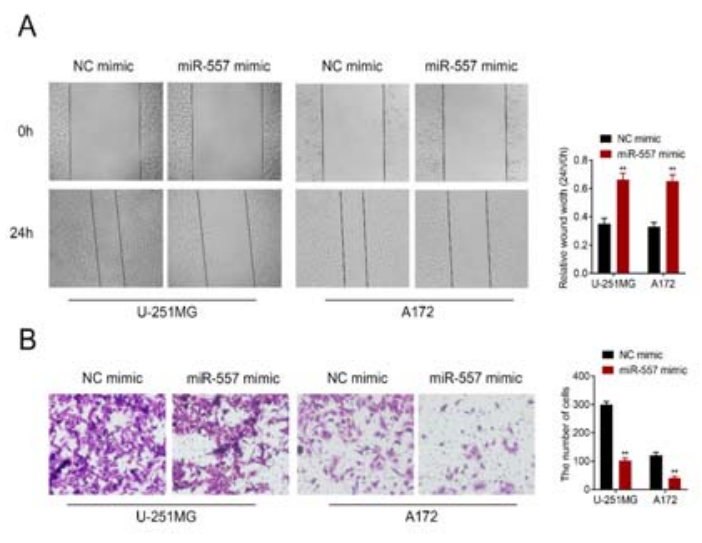

Figure 2: MiR-557 inhibited GBM cell migration and invasion. (A) Relative wound width was increased by miR-557 mimics; (B) The number of invaded cells was reduced by miR-557 mimics; ${ }^{* *} p<0.01$ vs. NC mimics

\section{MiR-557 repressed EMT in GBM cells}

Protein expression was determined using western blotting. In A172 and U-251MG cells that transfection of miR-557 mimics, the upregulation of E-cad and downregulation of $\mathrm{N}$-cad and Vim were found when compared with NC mimics (Figure $3 \mathrm{~A}-3 \mathrm{~B}$ ). 
A

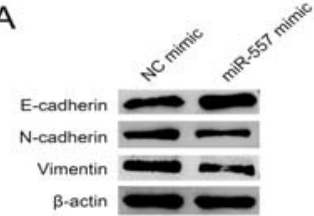

B

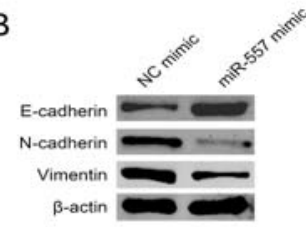

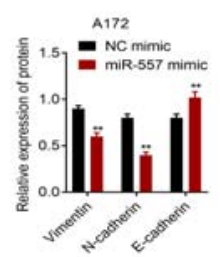

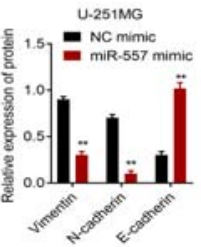

Figure 3: MiR-557 repressed EMT in GBM cells. Ecad, $\mathrm{N}$-cad, and Vim expression levels were changed by miR-557 mimics in A172 (A) and U-251MG cells (B); ${ }^{* *} p<0.01$ vs. NC mimics

\section{ADAM17 was the direct target of miR-557}

Prediction results of TargetScan (www.targetscan.org) demonstrated that there was a complementary sequence between miR557 and the 3'-UTR of ADAM17 (Figure 4A). The reduction in the luciferase activity was observed in cells that co-transfection of ADAM17-WT and miR-557, whereas there was no significant change in cells co-transfected with ADAM17MUT and miR-557 in both A172 and U-251MG cells (Figure $4 \mathrm{~B}$ ). Expression of ADAM17, NICD, HES1, and EGFR was decreased by miR-557 mimics, whereas expression of these proteins was increased by inhibition of miR-557 in both A172 cells (Figure 4C) and U-251MG cells (Figure 4D).

A

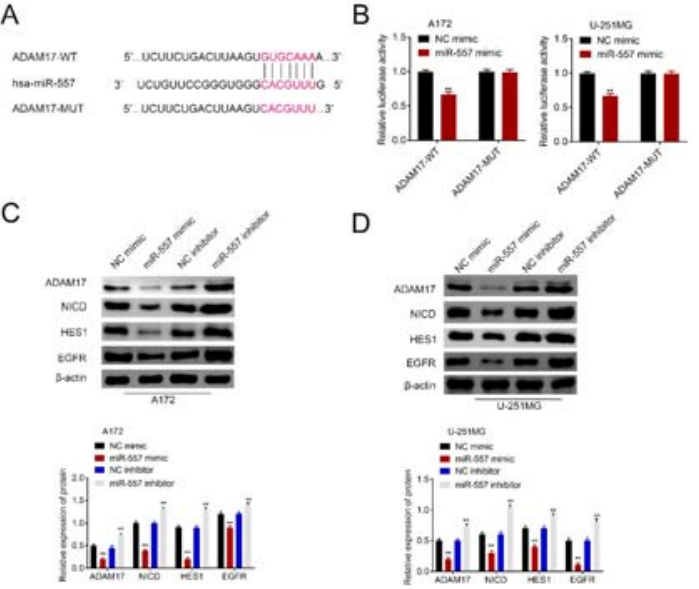

Figure 4: ADAM17 was the direct target of miR-557. (A) TargetScan predicted a complementary sequence between miR-557 and the 3'-UTR of ADAM17; (B) Luciferase activity was decreased in cells that cotransfection of miR-557 mimics and ADAM17-WT plasmid; (C) Expression of ADAM17, NICD, HES1, and EGFR was downregulated by miR-557 mimics and upregulated by miR-557 inhibitors in A172 cells; (D) Expression of ADAM17, NICD, HES1, and EGFR was downregulated by miR-557 mimics and upregulated by miR-557 inhibitors in U-251MG cells. ** $p<0.01$ vs. NC mimics or NC inhibitors

\section{DISCUSSION}

The prognosis of GBM is poor, with an average survival time of $12-15$ months [2]. Due to the lack of standard considering the care for recurrent GBM, new therapeutic strategies should be investigated to improve patient outcomes and prolong patient life [15]. Here, the downregulation of miR-557 was found in GBM cell lines. Further experiments demonstrated that ADAM17 was a direct target of miR-557. Through binding to ADAM17, miR-557 could reduce the proliferative, migratory, and invasive abilities of GBM cells, suggesting that miR-557 and ADAM17 might be prognostic biomarkers and potential therapeutic targets for new drug discovery in GBM.

Many studies have reported the downregulation of miR-557 in solid tumors and functions as a tumor suppressor $[16,17]$. Similar to previous findings, miR-557 expression was reduced in GBM cells in this study. Further experiments showed that miR-557 mimics suppressed the proliferative, migratory, and invasive of GBM cells, indicating an inhibitory effect on the development of GBM, which is consistent with previous studies $[16,17]$.

Results from TargetScan showed that there is a sequence complementary to a sequence in the ADAM17 3'-UTR in miR-557, which is the cocalled "seed region" of miRNAs [9], suggesting that ADAM17 might directly target to miR-557. This conclusion was further validated by luciferase assay. Western blotting verified that expression of ADAM17 was reduced by miR-557 mimics and increased by miR-557 inhibitors, indicating that miR-557 inhibited the translation of ADAM17 mRNA. These data prove that ADAM17 is the direct target of miR-557.

Unlike miR-557, ADAM17 is upregulated in many cancers, and has been shown to promote the pathogenesis of many cancers [18]. It has been reported that ADAM17 can cleave Notch and release NICD, and overexpression of NICD in cancers contributes to cancer metastasis $[19,20]$. Hairy and Enhancer of Split 1 (HES1) is the target of the Notch pathway, and EGFR is a substrate of ADAM17, which also promotes cancer development [6-21]. In the current study, ADAM17 expression was positively related to the expression levels of NICD, HES1, and EGFR. 
These data demonstrate that miR-557 targets the 3'-UTR of ADAM17 mRNA to inhibit ADAM17 protein expression, thereby blocking the downstream signaling pathway, resulting in prevention of GBM development.

\section{CONCLUSION}

This study has demonstrated the downregulation of miR-557 in GBM cell lines. Further experiments demonstrated that, through binding to ADAM17, miR-557 could reduce the proliferative, migratory, and invasive of GBM cells, and prevents EMT in GBM cells, suggesting that miR-557 and ADAM17 might be prognostic biomarkers and potential therapeutic targets for new drug discovery in GBM.

\section{DECLARATIONS}

\section{Conflict of interest}

No conflict of interest is associated with this work.

\section{Contribution of authors}

We declare that this work was done by the authors named in this article and all liabilities pertaining to claims relating to the content of this article will be borne by the authors. Zongping $\mathrm{Li}$ and Hongyuan Liu contributed equally to the work Zongping $\mathrm{Li}$ and Hongyuan Liu designed the study, supervised the data collection, Zhi Tang, Qi Zhong and Xu Yang analyzed the data, interpreted the data, Ye Zhang, Pengcheng He and Xiaoyi Wang prepare the manuscript for publication and reviewed the draft of the manuscript. All authors have read and approved the manuscript.

\section{Open Access}

This is an Open Access article that uses a funding model which does not charge readers or their institutions for access and distributed under the terms of the Creative Commons Attribution License (http://creativecommons.org/licenses/by/ 4.0) and the Budapest Open Access Initiative (http://www.budapestopenaccessinitiative.org/rea d), which permit unrestricted use, distribution, and reproduction in any medium, provided the original work is properly credited.

\section{REFERENCES}

1. Wirsching H-G, Galanis E, Weller M: Chapter 23 Glioblastoma. In: Handbook of Clinical Neurology.
Edited by Berger MS, Weller M, vol. 134: Elsevier; 2016 : 381-397.

2. Dapeng Zhu CSXQ. MST1 suppresses viability and promotes apoptosis of glioma cells via upregulating SIRT6 expression. J Integrative Neurosci 2019; 18(2): 117-126.

3. Saadatpour L, Fadaee E, Fadaei S, Nassiri Mansour R, Mohammadi M, Mousavi SM, Goodarzi M, Verdi J, Mirzaei H. Glioblastoma: exosome and microRNA as novel diagnosis biomarkers. Cancer Gene Ther 2016; 23(12): 415-418.

4. Le Rhun $E$, Preusser $M$, Roth $P$, Reardon $D A$, van den Bent $M$, Wen $P$, Reifenberger $G$, Weller M. Molecular targeted therapy of glioblastoma. Cancer Treat Rev 2019; 80:101896.

5. Aldape K, Zadeh G, Mansouri S, Reifenberger G, von Deimling A. Glioblastoma: pathology, molecular mechanisms and markers. Acta Neuropathologica 2015; 129(6): 829-848.

6. Düsterhöft S, Lokau J, Garbers C. The metalloprotease ADAM17 in inflammation and cancer. Pathol - Res Pract 2019; 215(6): 152410.

7. Chen X, Chen L, Chen J, Hu W, Gao H, Xie B, Wang X, Yin $Z, \quad L i$ S, Wang $X$. ADAM17 promotes U87 glioblastoma stem cell migration and invasion. Brain Res 2013; 153: 8151-158.

8. Zhang C, Han X, Xu X, Zhou Z, Chen X, Tang Y, Cheng $J$, Moazzam NF, Liu F, Xu J et al. FoxM1 drives ADAM17/EGFR activation loop to promote mesenchymal transition in glioblastoma. Cell Death Dis 2018; 9(5): 469.

9. Liu $X$, Chen $L$, Liu $Y$, Zhang T. Tangeretin sensitises human lung cancer cells to TRAIL-induced apoptosis via ROS-JNK/ERK-CHOP pathway-mediated up-regulation of death receptor 5. Trop J Pharm Res 2017; 16(1): 1729.

10. Lam JK, Chow MY, Zhang Y, Leung SW. siRNA Versus miRNA as Therapeutics for Gene Silencing. Mol Ther Nucleic Acids 2015; 4(9): e252.

11. Li W, Dong X, Zhao J. MiR-28-3p enhances healing of fracture via negative regulation of the target gene Sox6 and activation of PI3K/Akt signaling pathway. Trop $\mathrm{J}$ Pharm Res 2020; 19(10): 2061-2066.

12. Ganju A, Khan S, Hafeez BB, Behrman SW, Yallapu MM, Chauhan SC, Jaggi M. miRNA nanotherapeutics for cancer. Drug Discov Today 2017; 22(2): 424-432.

13. Xu T-J, Qiu P, Zhang Y-B, Yu S-Y, Xu G-M, Yang W. MiR-148a inhibits the proliferation and migration of glioblastoma by targeting ITGA9. Human Cell 2019; 32(4): 548-556.

14. Livak KJ, Schmittgen TD. Analysis of relative gene expression data using real-time quantitative $P C R$ and the 2(-Delta Delta C(T)) Method. Methods 2001; 25(4): 402-408.

15. Seystahl K, Wick W, Weller M. Therapeutic options in recurrent glioblastoma--An update. Crit Rev Oncol Hematol 2016; 99(389-408.

Trop J Pharm Res, February 2021; 20(2): 261 
16. Qiu J, Hao Y, Huang S, Ma Y, Li X, Li D, Mao Y. MiR-557 works as a tumor suppressor in human lung cancers by negatively regulating LEF1 expression. Tumour Biol 2017; 39(6): 1010428317709467.

17. Yang $Y$, Sun $K K$, Shen $X J, W U X Y, L i D C$. miR-557 inhibits the proliferation and invasion of pancreatic cancer cells by targeting EGFR. Int J Clin Exp Pathol 2019; 12(4): 1333-1341.

18. Rossello A, Nuti E, Ferrini S, Fabbi M. Targeting ADAM17 Sheddase Activity in Cancer. Curr Drug Targets 2016; 17(16): 1908-1927.
19. Venkatesh $V$, Nataraj $R$, Thangaraj GS, Karthikeyan $M$, Gnanasekaran A, Kaginelli SB, Kuppanna G, Kallappa CG, Basalingappa KM. Targeting Notch signalling pathway of cancer stem cells. Stem Cell Investig 2018; $5(5$.

20. Bozkulak EC, Weinmaster G. Selective use of ADAM10 and ADAM17 in activation of Notch1 signaling. Mol Cell Biol 2009; 29(21): 5679-5695.

21. Chen $X$, Chen $L$, Zhang $R$, Yi $Y, M a Y$, Yan $K$, Jiang $X$, Wang $X$. ADAM17 regulates self-renewal and differentiation of U87 glioblastoma stem cells. Neurosci Letters 2013; 537(44-49). 